\title{
Sergančiųjų alerginiu rinitu gyvenimo kokybės ir klinikinių simptomų pokytis taikant intranazalinę fototerapiją
}

\author{
CHANGES IN QUALITY OF LIFE AND CLINICAL SYMPTOMS IN PATIENTS \\ WITH ALLERGIC RHINITIS AFTER INTRANASAL PHOTOTHERAPY
}

\author{
JUSTINA ŠEMATONYTĖ, IEVA BAJORIŪNIENĖ, BRIGITA ŠITKAUSKIENĖ \\ LSMU MA Imunologijos ir alergologijos klinika
}

\begin{abstract}
Santrauka. Žinoma, kad fototerapija teigiamai veikia imuninius procesus gleivinèje. Yra duomenų, kad intranazalinè fototerapija (IF), skleidžianti UV-A (25 proc.), UV-B (5 proc.) ir regimąją šviesą (70 proc.), gali būti veiksminga gydant alerginị rinitą (AR) nepriklausomai nuo simptomus sukèlusio alergeno, taip pat gali būti taikoma ieškant alternatyvų medikamentiniam gydymui. Tyrimo tikslas. Ivvertinti intranazalinès fototerapijos poveikị klinikiniams alerginio rinito simptomams ir gyvenimo kokybei pacientų, sergančių nuolatiniu AR. Tyrimo metodai. Tyrimas atliktas Lietuvos sveikatos mokslų universiteto ligoninės Kauno klinikų Imunologijos ir alergologijos klinikoje. Jame dalyvavo sergantieji nuolatiniu vidutinio sunkumo arba sunkiu AR (ARIA diagnostiniai kriterijai). Alerginis ịsijautrinimas patvirtintas odos dūrio mèginiais ir (arba) specifinio imunoglobulino E (Ig E) antikūnų ịkvejpiamiems alergenams nustatymu kraujo serume. IF procedūros kartotos tris kartus per savaitę, dviejų savaičių laikotarpiu didinant dozę. Standartinis AR gydymas tyrimo metu nebuvo tęstas. Prieš ir po IF gydymo gyvenimo kokybė vertinta pagal E. Juniper adaptuotą klausimyną (angl. the Rhinoconjunctivitis Quality of Life Questionnaire, standardized version, RQLQ(s)), ịvertintas bendrasis nosies simptomų balas (angl. Total Nasal Symptom Score, TNSS). Kiekvienos procedūros metu, naudojant vizualinę atitikmens skalę (angl. Visual Analogue Scale, VAS), ịvertintas AR klinikinių simptomų sunkumas. Tyrimo rezultatai. 73 proc. tiriamųjų IF poveikị ịvertino teigiamai. Nustatyta, kad po IF gydymo pagerèjo tiriamųjų gyvenimo kokybė, nes statistiškai reikšmingai sumažejo Klausimyno (RQLQ(s)) visų poskalių balai. Po gydymo statistiškai reikšmingai sumažejjo visi TNSS skalès balai: nosies užgulimas, rinorejja, čiaudulys, miego sutrikimai, bendrieji simptomai. VAS skalès balai po gydymo taip pat sumažèjo statistiškai reikšmingai. Išvados. Intranazinė fototerapija gali palengvinti AR simptomus ir pagerinti pacientų gyvenimo kokybę.
\end{abstract}

Reikšminiai žodžiai: alerginis rinitas, intranazalinė fototerapija, nosies simptomų bendrasis balas, Sergančiųjų alerginiu rinitu gyvenimo kokybès klausimynas.

Summary. It is known that phototherapy has a positive effect on the immune processes in the mucous membrane. Recently, it was proven that intranasal phototherapy (IP) with combination of UVA (25\%), UVB (5\%) and visible light (70\%) can be effective in treating allergic rhinitis (AR) irrespective of symptom-induced allergen and it is recommended as alternatives to medication. Aim - to investigate the effect of intranasal phototherapy on clinical symptoms and quality-of-life of patients with persistent allergic rhinitis. Methods. A study of patients with confirmed persistent moderate-severe AR was carried-out at the department of Immunology and Allergology at the Kaunas Clinics of Lithuanian University of Health Sciences Hospital. Allergic sensitization was evaluated by skin prick and/or measurement of specific Ig E to aeroallergens. IP was applied three times a week for two weeks continuously with increasing doses. Standard AR treatment was not continued during the study. Assessment with rhinoconjunctivitis quality of life questionnaire (RQLQ(s)) and total nasal symptom score (TNSS) was performed before and after the treatment. The clinical symptoms were evaluated by visual analogue scale (VAS) during each procedure. Results. $73 \%$ of studied patients $(n=11)$ evaluated positively the effect of IP. Quality-of-life of studied subjects improved significantly after the treatment. The treatment reduced all symptoms evaluated by TNSS: nasal congestion, rhinorrhea, sneezing, difficulty to sleep and total score. VAS scores were also reduced significantly after the procedures. Conclusions. Intranasal phototherapy may relieve symptoms of allergic rhinitis and improve quality-of-life of the patients.

Keywords: allergic rhinitis, intranasal phototherapy, total nasal symptom score, rhinoconjunctivitis quality of life questionnaire.

\section{IVADAS}

Alerginis rinitas (AR) - tai viena labiausiai paplitusių lètinių ligų Europoje, dažniausiai prasidedanti ankstyvame amžiuje ir išliekanti visą gyvenimą [1]. AR pasireiškia pacientams, kurių imuninè sistema gamina specifinius antikūnus, imunoglobuliną E (Ig E), esant ìsijautrinimui tam tikriems oro alergenams, pvz., žiedadulkèms, namų dulkių erkutėms, naminių gyvūnų epidermio ląstelèms. Dažniausi AR klinikiniai simptomai pradinèje fazèje yra čiaudulys, nosies niežèjimas, 


\section{Moksliniai darbai ir apžvalgos}

rinorèja, vèlesnèje fazèje vyrauja nosies užgulimas [2]. Svarbu pabrèžti, kad lètinè AR eiga gali sukelti pacientams kasdienị diskomfortą, fizines ir emocines problemas. Galimos AR pasekmès: sutrikęs miegas, susilpnèjusi uoslè ir skonio jutimas, socialinio gyvenimo trikdžiai. Tinkamas AR gydymas gali palengvinti ligos naštą ir pagerinti pacientų gyvenimo kokybę [3].

Fototerapija ilgus metus sèkmingai taikoma uždegiminių odos ligų gydymui (pvz., atopinio dermatito) [4]. Imuniniai ir uždegiminiai procesai nosies gleivineje yra panašūs ị procesus, vykstančius odoje [5]. Yra duomenų, kad intranazaliné fototerapija (IF), skleidžianti UV-A (25 proc.), UV-B (5 proc.) ir regimąją šviesą (70 proc.), gali būti veiksminga gydant AR nepriklausomai nuo simptomus sukèlusio alergeno [6]. IF veikimo mechanizmas yra sudètingas ir kompleksinis. IF mažina antigenų pateikimą dendritinėms ląstelèms, aktyvina imuninių ląstelių apoptozę ir slopina prouždegiminių mediatorių sintezę ir išsiskyrimą, todèl IF gali būti veiksminga priemonè nosies gleivinei gydyti [7]. IF gydo AR mažindama slogą, čiaudulị, nosies niežèjimą ir obstrukciją bei mažina riziką komplikacijų, tokių kaip, sinusitas, nosies polipozé, kvèpavimo takų infekcijos [6]. Šis gydymo metodas gali būti naudojamas ieškant alternatyvų medikamentiniam gydymui. IF rekomenduojama esant absoliučioms arba santykinėms medikamentinio gydymo kontraindikacijoms (pvz., nèštumas, žindymo laikotarpis), vengiant šalutinių medikamentinio gydymo reakcijų (raminamasis, migdomasis poveikis) [5].

Iki šiol Lietuvoje neatlikta klinikinių tyrimų, analizuojančių fototerapijos veiksmingumą ir poveiki pacientų, sergančių AR, gyvenimo kokybei ir klinikiniams simptomams. Pasaulyje publikuota tyrimų, analizuojančių IF veiksmingumą, tačiau duomenų apie ilgalaiki procedūrų taikymą ir saugumą, gydant AR, vis dar stinga. Šiame straipsnyje aptariami 15 pacientu, sergančių nuolatiniu vidutinio sunkumo arba sunkiu AR ir kuriems buvo taikytos IF procedūros, duomenys bei aptariami tyrimo rezultatai.

\section{METODIKA}

2017 m. spalio - lapkričio mèn. Lietuvos sveikatos mokslų universiteto ligoninès Kauno klinikų Imunologijos ir alergologijos klinikoje vykdytas tyrimas gavus Lietuvos sveikatos mokslų universiteto (LSMU) Bioetikos centro leidimą Nr. BEC-LSMU(R)-385. Tyrime dalyvavo pacientai, sergantys nuolatiniu vidutinio sunkumo arba sunkiu AR. AR sunkumas nustatytas remiantis Alerginio rinito ir jo ittakos astmai iniciatyva (angl. Allergic Rhinitis and its Impact on Asthma, ARIA) rekomenduojama klasifikacija [8]. Tiriamieji apsisprendimą dalyvauti tyrime patvirtino pasirašydami informuoto asmens sutikimo formą. Alerginis įsijautrinimas patvirtintas odos dūrio mèginiais (Allergy
1 lentelè. Intranazalinès fototerapijos procedūrų grafikas

\begin{tabular}{|l|c|}
\hline \multicolumn{1}{|c|}{ Procedūra } & $\begin{array}{c}\text { Procedūros trukmè nosies } \\
\text { landoje (min:sek.) }\end{array}$ \\
\hline 1 savaitė \\
\hline Pirmas IF seansas & $2: 00$ \\
\hline Antras IF seansas & $2: 15$ \\
\hline Trečias IF seansas & $2: 30$ \\
\hline 2 savaitė \\
\hline Ketvirtas IF seansas \\
\hline Penktas IF seansas & $2: 45$ \\
\hline Šeštas IF seansas & $3: 00$ \\
\hline
\end{tabular}

Therapeutics, Jungtinè Karalystė) ir (arba) specifinių Ig E antikūnų nustatymu ịkvepiamiems alergenams kraujo serume (EUROIMMUN, Vokietija). I tyrimą neįtraukti asmenys, turintys struktūrinius nosies pakitimus, nazofaringinę onkologinę anamnezę bei turejję viršutinių arba apatinių kvejpavimų takų infekciją keturių savaičių laikotarpiu iki tyrimo. IF procedūros kartotos tris kartus per savaitę dviejų savaičių laikotarpiu (1 lentelè). Gyvenimo kokybè vertinta pagal Gyvenimo kokybès, sergant alergine sloga, vertinimo klausimyną su standartiniais užsiemmimais (RQLQ(s)) pagal E. Juniper, gavus autorès sutikimą. Mažesnis skaičius skalèje rodė geresnę, didesnis - blogesnę gyvenimo kokybę per paskutinę savaitę. Prieš ir iškart po IF gydymo ịvertintas RQLQ(s) ir nosies simptomų bendrasis balas (angl. Total Nasal Symptom Score, TNSS). Kiekvienos procedūros metu, naudojant vizualinę atitikmens skalę (angl. Visual Analogue Scale, VAS), ivvertintas AR klinikinių simptomų sunkumas. Taip pat analizuoti duomenys apie ligos trukmę, sezoniškumą, simptomus skatinančius veiksnius, gretutines ligas, iprastinio gydymo vaistais poveikị. Duomenų analizė atlikta naudojantis SPSS 22.0 statistine programa. Nagrinẻjamų požymių pasiskirstymui pasirinktoje imtyje ivvertinti taikyti absoliutieji (n) ir procentiniai dydžiai (proc.). Siekiant palyginti kintamųjų skirtumus tarp dviejų priklausomų grupių, taikytas neparametrinis Vilkoksono (angl. Wilcoxon) kriterijus. Statistinėms hipotezėms tikrinti pasirinktas kriterijaus reikšmingumo lygmuo, kai $\mathrm{p}<0,05$.

\section{REZULTATAI}

Vidutinis tiriamųjų amžius - 30,86 \pm 11,67 metų (jauniausias - 18 metų, vyriausias - 52 metų). Iš viso tyrime dalyvavo trys vyrai ir 12 moterų. Tik vienas tiriamasis (tai sudarè 7 proc. tirtos populiacijos) prieš tai buvo girdèjęs ir susipažinęs su IF gydymu, likusieji 14 tiriamųjų (93 proc. tirtos populiacijos) apie ši gydymo būdą nežinojo. Vidutinè tirtų pacientų AR 


\section{Moksliniai darbai ir apžvalgos}

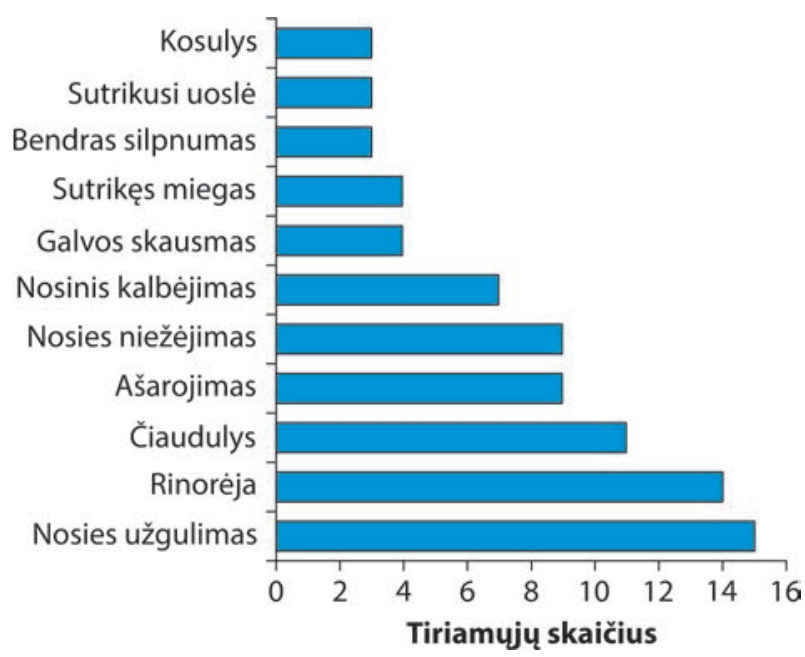

1 pav. Alerginio rinito klinikinių simptomų dažnis

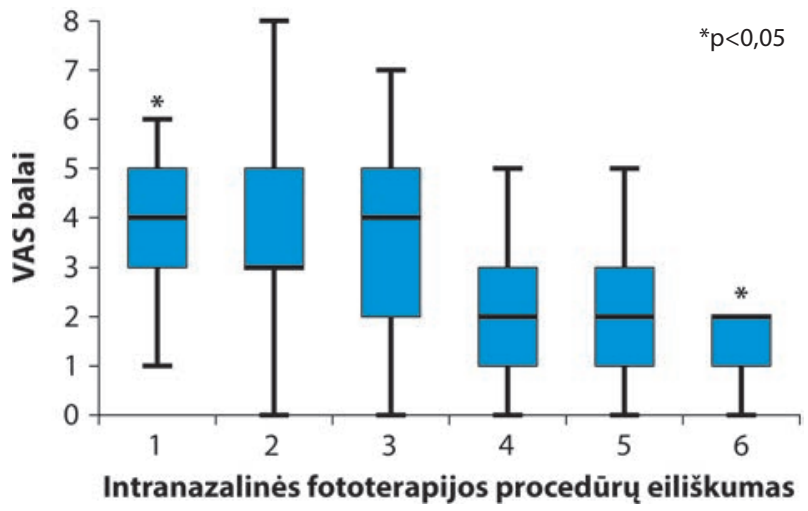

2 pav. Tiriamujų vizulinès analoginès skalès (VAS) ịvertinimas kiekvienos procedūros metu (* pateikiamas statistiškai reikšmingas VAS balų skirtumas tarp pirmos ir šeštos procedūrų)

ligos trukmè - 8,11 $\pm 8,13$ metų (trumpiausia ligos trukmé - vieneri metai, ilgiausia - 25 metai). Daugumai tiriamųjų ( $\mathrm{n}=8 ; 54$ proc.) AR klinikiniai simptomai pasireiškè vienodai dažnai paros laikotarpiu, 33 proc. ryškiausia klinika buvo rytą $(\mathrm{n}=5), 13$ proc. - vakare $(n=2)$. Dažniausiai vargino nosies užgulimas $(n=15$; 100 proc.), rinorejja ( $n=14 ; 93$ proc.) ir čiaudulys $(n=11$; 73 proc.). Klinikinių AR simptomų pasireiškimo analizė pateikiama diagramoje (1 pav.). Dažniausia gretutine patologija, kuri nustatyta tiriamiems pacientams, sergantiems AR, buvo astma $(n=4,27$ proc.), taip pat du tiriamieji sirgo atopiniu dermatitu (13 proc.). Visiems tiriamiesiems nustatytas alerginis įsijautrinimas namų dulkių erkių allergenams (Dermatophagoides pteronyssinus, Dermatophagoides farinae) $(\mathrm{n}=15)$, keturiems tiriamiesiems nustatytas isijautrinimas naminių gyvūnų alergenams (katè, šuo) (27 proc.), keturiems pacientams nustatytas ịsijaurinimas išorinès aplinkos, t. y. medžių (beržų), žolių (kietys, piktžolès) žiedadulkių alergenams (27 proc.).

73 proc. tiriamujuc $(n=11)$ IF poveiki AR klinikiniams simptomams įvertino teigiamai. Nustatyta, kad po IF
2 lentelè. Gyvenimo kokybès klausimyno (RQLQ(s)) poskalių balai prieš ir po gydymo

\begin{tabular}{|l|c|c|c|}
\hline \multicolumn{1}{|c|}{ RQLQ(s) } & $\begin{array}{c}\text { Prieš } \\
\text { gydymą }\end{array}$ & $\begin{array}{c}\text { Po } \\
\text { gydymo }\end{array}$ & p reikšmè \\
\hline Miego kokybe & $2,37 \pm 1,93$ & $1,15 \pm 0,72$ & 0,023 \\
\hline ltaka aktyvumui & $2,89 \pm 1,38$ & $1,31 \pm 0,73$ & 0,003 \\
\hline Nosies simptomai & $2,78 \pm 1,54$ & $1,38 \pm 0,92$ & 0,013 \\
\hline Akių simptomai & $1,98 \pm 1,80$ & $0,88 \pm 0,91$ & 0,005 \\
\hline ltaka emocijoms & $2,03 \pm 1,45$ & $1,16 \pm 1,18$ & 0,047 \\
\hline Fizinės problemos & $3,62 \pm 1,91$ & $1,84 \pm 1,32$ & 0,014 \\
\hline $\begin{array}{l}\text { Kiti varginę } \\
\text { simptomai }\end{array}$ & $1,99 \pm 1,25$ & $1,16 \pm 1,04$ & 0,010 \\
\hline
\end{tabular}

3 lentelè. Nosies simptomai (TNSS) prieš ir po gydymo

\begin{tabular}{|l|c|c|c|}
\hline \multicolumn{1}{|c|}{ TNSS } & $\begin{array}{c}\text { Prieš } \\
\text { gydymą }\end{array}$ & $\begin{array}{c}\text { Po } \\
\text { gydymo }\end{array}$ & $\begin{array}{c}\mathbf{p} \\
\text { reikšmė }\end{array}$ \\
\hline Nosies užgulimas & $2,00 \pm 1,00$ & $1,13 \pm 0,64$ & 0,015 \\
\hline Rinorèja & $2,00 \pm 1,00$ & $1,13 \pm 0,64$ & 0,015 \\
\hline Čiaudulys & $1,53 \pm 1,06$ & $0,67 \pm 0,61$ & 0,026 \\
\hline Niežèjimas & $1,27 \pm 1,01$ & $0,20 \pm 0,56$ & 0,008 \\
\hline Bendrieji balai & $8,67 \pm 4,01$ & $4,07 \pm 2,12$ & 0,020 \\
\hline
\end{tabular}

4 lentelè. Nosies simptomai (TNSS) po paskutinès procedūros ir praejjus 6 mèn. po gydymo

\begin{tabular}{|l|c|c|c|}
\hline \multicolumn{1}{|c|}{ TNSS } & $\begin{array}{c}\text { Iš karto } \\
\text { po gydymo }\end{array}$ & $\begin{array}{c}\text { Po } \\
\mathbf{6} \text { mėn. }\end{array}$ & $\begin{array}{c}\mathbf{p} \\
\text { reikšmė }\end{array}$ \\
\hline Nosies užgulimas & $1,13 \pm 0,64$ & $1,17 \pm 0,84$ & 0,001 \\
\hline Rinorèja & $1,13 \pm 0,64$ & $2,08 \pm 0,90$ & 0,082 \\
\hline Čiaudulys & $0,67 \pm 0,61$ & $1,25 \pm 0,96$ & 0,200 \\
\hline Niežejimas & $0,20 \pm 0,56$ & $1,08 \pm 0,90$ & 0,128 \\
\hline Bendrieji balai & $4,07 \pm 2,12$ & $5,50 \pm 3,80$ & 0,062 \\
\hline
\end{tabular}

gydymo tiriamųjų gyvenimo kokybė pagerèjo, nes statistiškai reikšmingai sumažèjo tiriamųjų RQLQ(s) visų poskalių balai: miego kokybè, AR simptomų itaka aktyvumui, nosies simptomai, akių simptomai, AR simptomų itaka emocijoms, praktinès problemos (nepatogumas, kad reikia su savimi nešiotis popierines servetèles arba nosinę, poreikis nuolat pūsti nosị) ir kiti varginę bendrieji simptomai $(\mathrm{p}<0,05)$ (2 lentelè). Po gydymo statistiškai reikšmingai sumažejo visi TNSS skalès balai: nosies užgulimas, rinorèja, čiaudulys, niežejimas, bendrieji simptomai $(\mathrm{p}<0,05)$ (3 lentelè). VAS skalès balai tai pat statistiškai reikšmingai sumažèjo po gydymo $(4,00 \pm 1,51$ palyginus su $1,60 \pm 1,24 ; \mathrm{p}=0,003)$ (2 pav.). Tyrimo rezultatai patvirtino IF gamintoju pateikiamą informaciją, kad, pradejus gydymą, gali paūmèti AR klinikiniai simptomai. 33 proc. tiriamųju 


\section{Moksliniai darbai ir apžvalgos}

$(\mathrm{n}=5)$ nurodè AR klinikinių simptomų paūmèjimą procedūrų pradžioje. Taip pat trečdalis pacientų $(n=5)$ skundèsi atsiradusiu nosies gleivinès sausumu, tačiau tik 20 proc. tiriamujuç atsižvelgè i rekomendacijas vartoti emolientus (pvz., vitamino A aliejų). Gydymo pabaigoje tiriamųjų buvo paprašyta ịvertinti dešimtabaleje sistemoje IF veiksmingumą palengvinant AR klinikinius simptomus. Vidutinė įverčio vertẻ buvo 7,46 $\pm 1,19$ (mažiausia verte் $-5,00$; didžiausia verte 9,00). Tiriamieji buvo apklausti praejjus 6 mèn. po gydymo. Vidutiné simptomų atsinaujinimo pradžia, praèjus 2,75 mèn. po taikytų procedūrų (min. -0 mèn.; maks. -6 mèn.). Praejjus 6 mèn. po gydymo statistiškai reikšmingai padidejjo rinorèjos, čiaudulio, niežejjimo ir TNSS balai, tik TNSS nosies užgulimo balas statistiškai reikšmingai neišsiskyrè praejjus 6 mèn. po IF procedūrų (žr. 4 lentelę).

\section{REZULTATŲ APTARIMAS}

Šio tyrimo rezultatai parode, kad IF gali palengvinti AR klinikinius simptomus ir pagerinti pacientu gyvenimo kokybę. Anksčiau skelbtų mokslinių publikacijų rezultatai diskutuotini. Vieni autoriai teigia, kad IF yra saugi ir veiksminga gydymo priemonė gydyti tiek nuolatiní, tiek epizodinị AR [9-12]. Kiti autoriai nurodo, kad IF nèra pakankamai veiksmingas AR gydymo metodas [13]. Šiame tyrime buvo naudoti standartizuoti klausimynai, dèl to šio tyrimo rezultatus galima palyginus su kitu autorių analogiškais tyrimais.

2017 m. Sun L. su bendraautoriais (Kinija) atlikta sisteminè metaanalizé, kurioje buvo apžvelgta 12 straipsnių bei 7 klinikiniai tyrimai (PubMed, Embase, Cochrane duomenų bazès), kuriuose dalyvavo 615 suaugusiųjų, sergančių AR ir kuriems buvo taikyta IF. Metaanalizès rezultatai rodo, kad IF gali pagerinti TNSS ir RQLQ įverčius, taip pat patvirtintas geras procedūros saugumo profilis [9]. Šioje metanalizèje pateikti rezultatai panašūs i atlikto tyrimo rezultatus bei išvadas. Taip pat metaanalizèje aprašomas tiriamiesiems IF procedūrų metu atsiradęs nosies gleivinès sausumas [9]. Šiame tyrime nustatyta, kad trečdalis tiriamujų $(\mathrm{n}=5)$ skundèsi atsiradusiu nosies gleivinès sausumu gydymo metu.

Vienas pirmųjų 2005 m. paskelbtas Koreck AL. ir kolegu (Vengrija) tyrimas parodè, kad IF buvo gerai toleruojama ir po gydymo reikšmingai pagerẻjo TNSS skalès balai: čiaudulys $(\mathrm{p}=0,016)$, rinoreja $(\mathrm{p}=0,007)$, nosies niežejimas $(\mathrm{p}=0,014)$ ir bendras nosies kiekis $(\mathrm{p}=0,004)$. Tuo tarpu nè vienas iš simptomų kontrolinèje grupeje nepagerèjo [10]. $2013 \mathrm{~m}$. Lee HM ir kolegų (Korèja) tyrimo rezultatai parode, kad net 68 proc. tiriamuju IF procedūras vertino teigiamai ir jautè AR klinikinių simptomų palengvejimą. Po gydymo pastebètas reikšmingas nosies užgulimo $(\mathrm{p}=0,001)$, rinorejos $(\mathrm{p}=0,005)$, čiaudulio $(\mathrm{p}=0,001)$ ir niežèjimo $(\mathrm{p}=0,003)$ sumažejjimas [11]. Šiame tyrime 73 proc. tiriamųjų $(\mathrm{n}=11)$ IF poveiki AR klinikiniams simptomams įvertino teigiamai. Po procedūrų statistiškai reikšmingai palengvejo nosies užgulimas $(p=0,015)$, rinorèja $(\mathrm{p}=0,015)$, čiaudulys $(\mathrm{p}=0,026)$, niežèjimas $(p=0,008)$, bendrieji simptomai $(p=0,02)$. Šiame tyrime kontrolinès grupès nebuvo.

2017 m. Bella Z. su bendraautoriais (Vengrija) paskelbtas tyrimas, kurio metu analizuotas IF veiksmingumas su placebo grupe. Tyrime dalyvavo 34 pacientai, sergantys nuolatiniu AR. Tiriamieji buvo atsitiktinai suskirstyti į dvi grupes. Pirma grupe buvo gydoma UV-B, UV-A ir didelio intensyvumo matomąja šviesa, antrai grupei buvo skiriamos mažo intensyvumo regimosios šviesos procedūros. Buvo vertinamas TNSS balas ir uoslès rodmens slenkstis. Visi TNSS skalès balai ir uosle pacientams, gydytiems IF, reikšmingai pagerèjo. Nors Bella Z. su bendraautoriais tiriamųjų imtis buvo dukart didesné nei šio tyrimo ( $n=34$; vs. $n=15)$, tačiau šalutinių reakcijų procedūrų metu nepastebèta [12]. Tuo tarpu atlikto tyrimo rezultatai parodè, $\mathrm{kad} 33$ proc. tiriamụjų $(n=5)$ jaute AR klinikinių paūmèjima gydymo pradžioje, taip pat 33 proc. $(n=5)$ skundèsi atsiradusiu nosies gleivinès sausumu.

2017 m. Dulguerov N. ir bendraautorių (Šveicarija) tyrimas parodè, kad IF nèra pakankamai veiksmingas AR gydymo metodas. Lyginant gydytos IF ir placebo grupès (RQLQ(s)) vertes, statistiškai reikšmingų skirtumų nenustatyta $(p<0,05)[13]$. Šiame tyrime placebo grupès nebuvo.

Iprastinis AR gydymas paremtas tarptautinio susitarimo taisyklèmis [8]. Pirmiausia reikia šalinti aplinkoje esančius alergenus ir vengti nespecifinių dirgiklių. Medikamentinis AR gydymas yra pakopinis ir priklauso nuo ligos sunkumo bei klinikinès eigos. Nuolatinis AR gydomas geriamaisiais arba intranazaliniais antihistaminiais vaistais ir intranazaliniais gliukokortikoidais. Dèl gydymo specifine imunoterapija sprendžiama, kai būklè negerèja gydant vaistais. Standartinèse alerginio rinito gydymo rekomendacijose IF procedūros nenurodomos $[8,14]$.

Gydymas IF vis dar išlieka diskusijų objektu. Tyrimų rezultatai rodo, kad IF veiksmingai palengvina AR simptomus ir gali būti rekomenduojamas kaip naujas, alternatyvus gydymo būdas. Atkreiptinas dèmesys, kad IF negali būti taikoma kaip AR simptomu profilaktikos priemonè. IF procedūros skiriamos jau esant AR klinikai. Duomenų apie ilgalaikį, pakartotini IF procedūrų taikymą vis dar stinga, todèl reikalingi didesnès tiriamụjų imties ir ilgesnès trukmès tyrimai.

\section{IŠVADOS}

Šio tyrimo duomenimis, IF gali palengvinti alerginio rinito klinikinius simptomus ir pagerinti pacientu, 


\section{Moksliniai darbai ir apžvalgos}

sergančių vidutinio sunkumo arba sunkiu alerginiu rinitu, gyvenimo kokybę.

Gauta 20180817

Priimta 20180904

\section{LITERATŨRA}

1. Wheatley LM, Togias A. Clinical practice. Allergic rhinitis. N Engl J Med. 2015; 372(5):456-63.

2. Karatzas K, Katsifarakis N, Riga M, Werchan B, Werchan M, Berger U, et al. New European Academy of Allergy and Clinical Immunology definition on pollen season mirrors symptom load for grass and birch pollen-induced allergic rhinitis. Allergy [Internet]. 2018; 73(9):1851-9.

3. Camelo-Nunes IC, Solé D. Allergic rhinitis: indicators of quality of life. J Bras Pneumol. 2010; 36(1):124-33.

4. Meduri NB, Vandergriff $T$, Rasmussen $H$, Jacobe $H$. Phototherapy in the management of atopic dermatitis: a systematic review. Photodermatol Photoimmunol Photomed. 2007; 23(4):106-12.

5. Koreck AI, Kenderessy AS, Kemeny L. Intranasal phototherapy is an effective treatment in allergic rhinitis. J Allergy Clin Immunol. 2006; 117(2):260

6. Brehmer D. Endonasal phototherapy with Rhinolight ${ }^{\otimes}$ for the treatment of allergic rhinitis. Expert Rev Med Devices. 2010; 7(1):21-6.

7. Kemény L, Koreck A. Ultraviolet light phototherapy for allergic rhinitis. J Photochem Photobiol B. 2007; 87(1):58-65.

8. Bousquet J, Khaltaev N, Cruz AA, Denburg J, Fokkens WJ, Togias A, et al. Allergic rhinitis and its impact on asthma (ARIA) 2008 update (in collaboration with the World Health Organization, GA(2)LEN and AllerGen). Allergy. 2008; 63(Suppl 86):8-160.

9. Sun LN, Liu SY, Shuai CJ, Mao XM, Yin ZD. [Efficacy and safety of endonasal phototherapy in the treatment of adult allergic rhinitis: A Meta-analysis]. Lin Chung Er Bi Yan Hou Tou Jing Wai Ke Za Zhi. 2017; 31(24):1896-903;1909.

10. Koreck AI, Csoma Z, Bodai L, Ignacz F, Kenderessy AS, Kadocsa E, et al. Rhinophototherapy: a new therapeutic tool for the management of allergic rhinitis. J Allergy Clin Immunol. 2005; 115(3):541-7.

11. Lee H-M, Park MS, Park IH, Lee SH, Lee SK, Kim K-S, et al. A comparative pilot study of symptom improvement before and after phototherapy in Korean patients with perennial allergic rhinitis. Photochem Photobiol. 2013; 89(3):751-7.

12. Bella Z, Kiricsi Á, Viharosné ÉD-R, Dallos A, Perényi Á, Kiss M, et al. Rhinophototherapy in persistent allergic rhinitis. Eur Arch Otorhinolaryngol. 2017; 274(3):1543-50.

13. Dulguerov N, Guinand N, Courvoisier D, Landis BN, Lacroix JS, Hauser C. Rhinophototherapy in chronic rhinosinusitis: a double blind randomized placebo-controlled trial. Rhinology. 2017; 55(2):106-12.

14. Gotoh M. Allergic rhinitis: diagnosis and treatment based on the guidelines. Arerugi. 2018; 67(7):914-8. 